\title{
Influence of Haptoglobin on haemorrhage volume and oedema extension distance after intracerebral \\ haemorrhage
}

IC Hostettler, M Morton, D Wilson, G Ambler, C Shakeshaft, H R Jäger, H Houlden, H Cohen, T Yousry, R Al-Shahi Salman, GYH Lip, MM Brown, KW Muir, I Galea, DJ Werring

On behalf of the CROMIS Investigators, Stroke Research Group, UCL Institute of Neurology, National Hospital for Neurology and Neurosurgery, Queen Square, London, UK

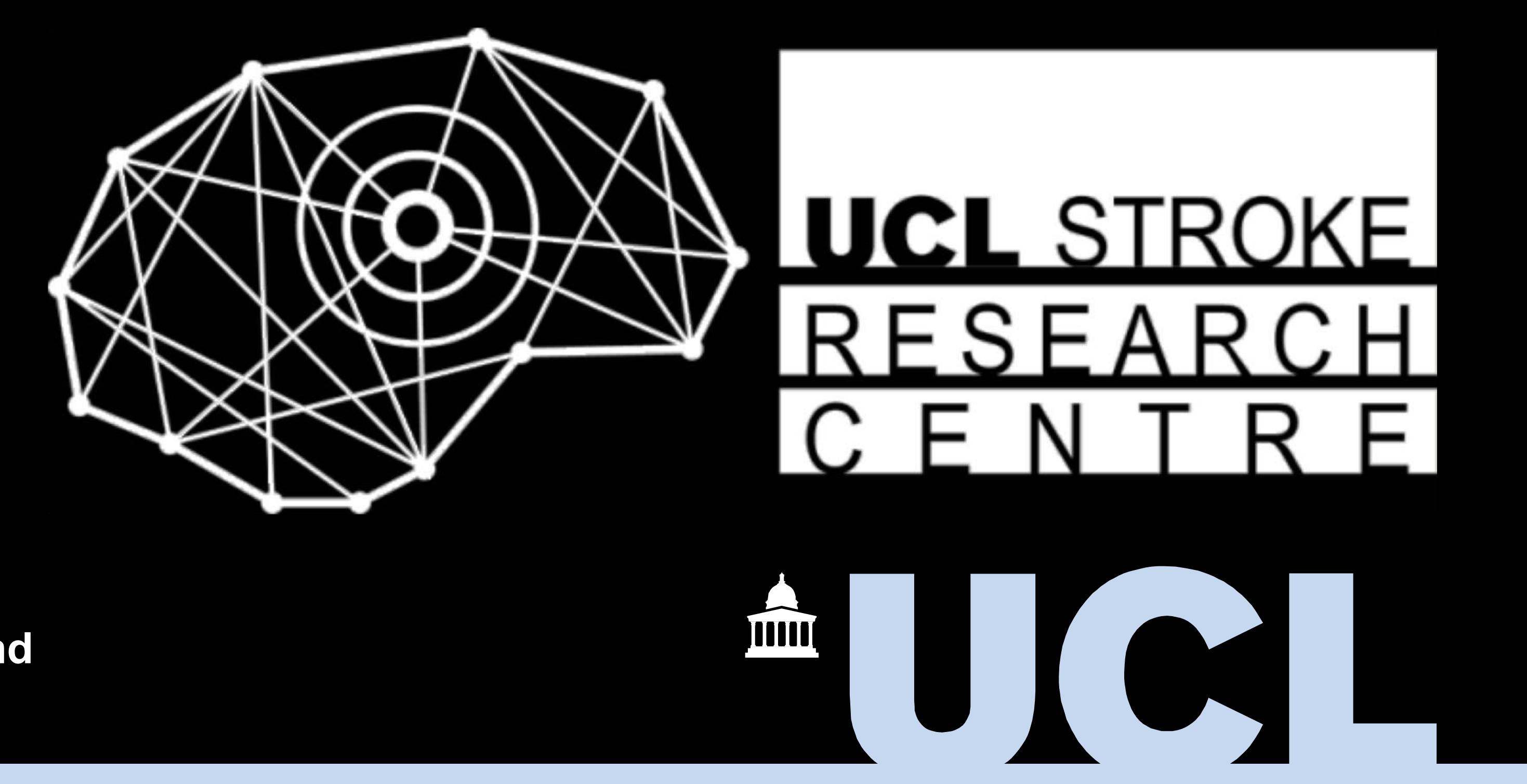

\section{Background}

After an intracerebral haemorrhage $(\mathrm{ICH})$ the brain is exposed to extarcellular haemoglobin and its toxic breakdown products haem and iron. Haptoglobin $(\mathrm{Hp})$ is an acute-phase protein involved in neutralizing haemoglobin. Hp expression level is influenced by the Hp copy number variant (CNV) (Hp1 versus $\mathrm{Hp} 2$ ), and the res2000999 single nucleotide polymorphism (SNP). Hp1-1 has previously been associated with better outcomes after $\mathrm{ICH}$.

We investigated the effect of these genetic variations on perihaemtaomel oedema (PHO), a potential mediator of effects on outcome, measured by oedema expansion distance (OED; potential marker of inflammation and haemoglobin toxicity).

\section{Methodology}

We enrolled patients from the ICH arm of the CROMIS-2 study, a prospective observational study. Hp CNV was determined by two methods: quantitative polymerase chain reaction (PCR) and conventional PCR.

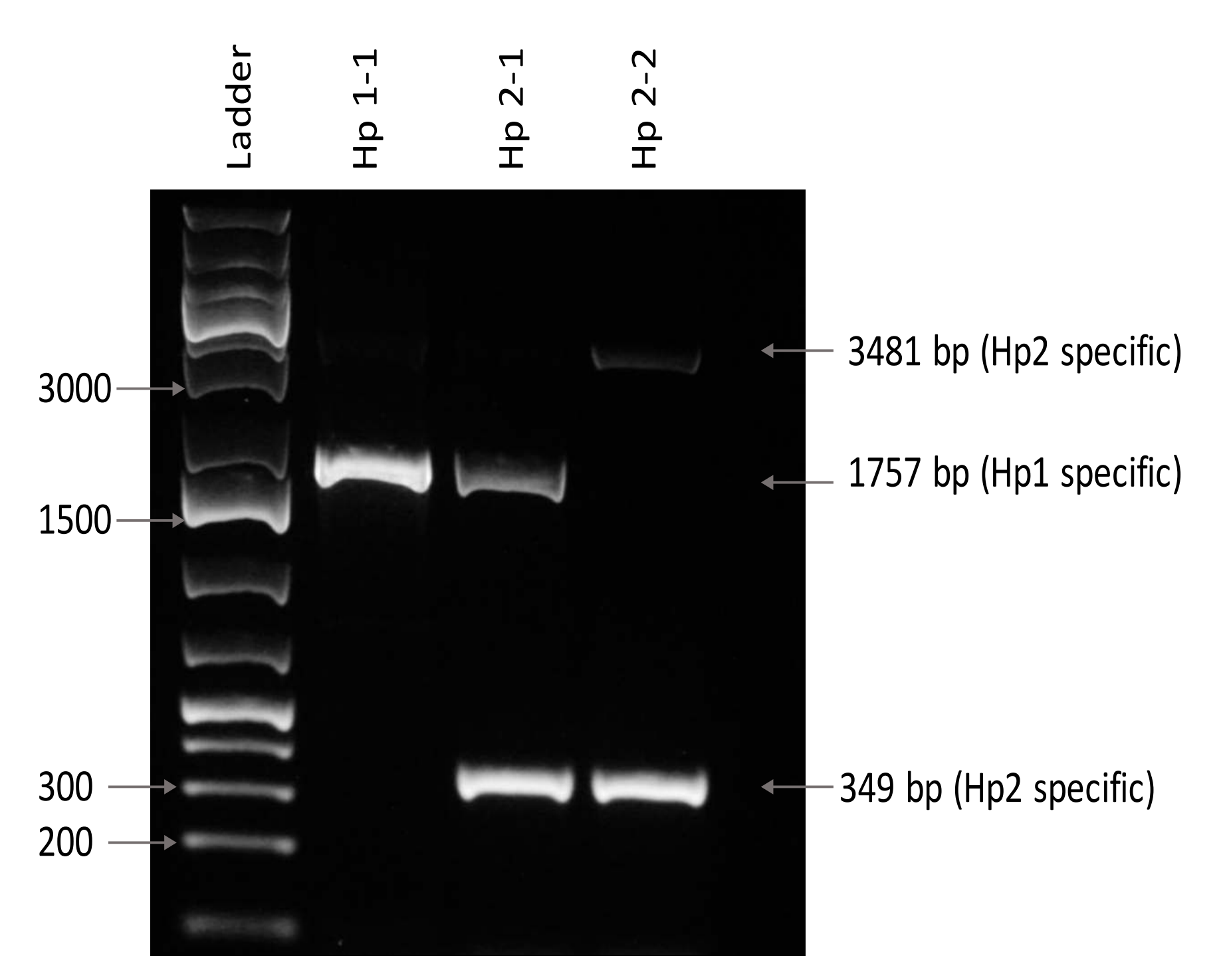

Lane 1 is a GeneRuler $1 \mathrm{~kb}$ plus ladder, lane 2 is the PCR product from a Hp1-1 individual, lane $3 \mathrm{Hp2}-1$ and permission from M. Morton, University of Southampton.

$\mathrm{Hp}$ SNP was determined using Kompetitive Allele-Specific PCR. Measurement of PHE volume on acute CT scan (within three days) was performed via semi-automated, threshold based approach.

\section{Results}

We included 738 included patients from the CROMIS-2 study with available blood samples. 317 were female $(42.95 \%)$ and mean age was 73.3 (SD 12.4). Mean ICH volume was 13.48 (SD 18.36) and mean OED volume was 0.51 (standard deviation $0.23)$. The distribution of the ICH location was as follows: 301 were lobar (41.23\%), 365 deep (50\%), 22 in the brainstem (3\%) and 42 in the cerebellum $(5.75 \%)$.

Hp CNV was $122 \mathrm{Hp} 1-1$ (16.55\%), $364 \mathrm{Hp} 2-1$ (49.39\%) and 244 Hp2-2 (34.06\%).

Figure 1: $H p C N V$

\begin{tabular}{|l|l|}
\hline Hp CNV & \\
\hline & \\
\hline Hp 1-1 & $122(16.55 \%)$ \\
\hline Hp 2-1 & $364(49.39 \%)$ \\
\hline Hp 2-2 & $251(34.06 \%)$ \\
\hline
\end{tabular}

Distribution of the Hp SNP genotype was: 23 A:A (3.22\%), 235 A:G (32.87) and $457 \mathrm{G:G}(63.92 \%)$.

Figure 2: $H p S N P$

\begin{tabular}{|c|c|}
\hline Hp genotype & \\
\hline & \\
\hline A:A & $23(3.22 \%)$ \\
\hline A:G & $235(32.87)$ \\
\hline G:G & $457(63.92)$ \\
\hline
\end{tabular}

Neither HP CNV nor SNP genotype was associated with OED in either univariable or multivariable linear regression analysis that included systolic blood pressure, antihypertensive medication, anticoagulation, time to $\mathrm{CT}$, ICH volume and location.

Figure 3: Final multivariable logistic regression model

\begin{tabular}{|c|c|c|c|}
\hline Variables & Coefficient & $95 \% \mathrm{Cl}$ & $P$ value \\
\hline SBP & 0.0003 & $-0.0003-0.0008$ & 0.36 \\
\hline OAC & 0.02 & $-0.04-0.07$ & 0.55 \\
\hline $\begin{array}{l}\text { Time Event to CT } \\
\text { - Dav } 1 \text { (reference) }\end{array}$ & & & 0.13 \\
\hline - Day 2 & 0.07 & $0.002-0.13$ & \\
\hline - Day 3 & 0.02 & $-0.08-0.12$ & \\
\hline $\mathrm{Cr}$ ICH volume & 0.04 & $0.02-0.06$ & $<0.001$ \\
\hline ICH location & & & $<0.001$ \\
\hline $\begin{array}{l}\text { - cerebellar } \\
\text { (reference) }\end{array}$ & & & \\
\hline - Brainstem & -0.04 & $-0.16-0.07$ & \\
\hline - Deep & 0.17 & $0.09-0.24$ & \\
\hline - Lobar & 0.23 & $0.15-0.3$ & \\
\hline $\begin{array}{l}\text { Antihypertensive } \\
\text { medication }\end{array}$ & -0.07 & $-0.12-(-0.01)$ & 0.01 \\
\hline Hp genotype & & & 0.44 \\
\hline - Hp1-1 (reference) & & & \\
\hline - Hp2-1 & -0.02 & $-0.07-0.02$ & \\
\hline - Hp2-2 & -0.03 & $-0.08-0.02$ & \\
\hline Rs2000999 & & & 0.28 \\
\hline - A:A (reference) & & & \\
\hline$-A: G$ & 0.003 & $-0.09-0.1$ & \\
\hline - G:G & -0.03 & $-0.12-0.07$ & \\
\hline
\end{tabular}

\section{Conclusion}

We found no association of either Hp CNV or SNP with acute $\mathrm{PHO}$ : If haptoglobin genetic variant influence outcome, it is likely mediated by mechanisms other than through reducing acute $\mathrm{PHO}$. 